\title{
Approaches Towards Professional Studies and Spare-time Activities Among Preclinical and Clinical Year Medical Students
}

Tahir Jameel ${ }^{1}$, Mukhtiar Baig ${ }^{2}$, Zohair J. Gazzaz ${ }^{1}$, Jawad M. Tashkandi ${ }^{3}$, Nasser S. Al Alhareth $^{3}$, Shahida A. Khan ${ }^{4}$, Nadeem S. Butt ${ }^{5}$

1. Internal Medicine, King Abdulaziz University, Jeddah, SAU 2. Clinical Biochemistry, Medical Education, Faculty of Medicine, King Abdulaziz University, Jeddah, SAU 3. Miscellaneous, Faculty of Medicine, King Abdulaziz University, Jeddah, SAU 4. Community Medicine, King Fahad Medical Research Center, King Abdulaziz University, Jeddah, SAU 5. Medical Statistics, Faculty of Medicine, King Abdulaziz University, Jeddah, SAU

$\square$ Corresponding author: Tahir Jameel, tahirjameel@hotmail.com Disclosures can be found in Additional Information at the end of the article

\section{Abstract}

\section{Objective}

This study aims at a recognition of the differences in the study habits, approach to teaching resources, and spare-time activities of medical students in the preclinical and clinical training periods at King Abdulaziz University (KAU) Jeddah, Saudi Arabia (SA).

\section{Methods}

Study sampling was carried out in 2017 at the Faculty of Medicine, KAU, Jeddah, SA. Students from both genders were included and further subdivided to preclinical ( $2^{\text {nd }}$ and $3^{\text {rd }}$ years) and clinical groups $\left(4^{\text {th }}, 5^{\text {th }}\right.$, and $6^{\text {th }}$ years). Students were asked to respond to an online questionnaire. SPSS-Version 21 (IBM Corp., Armonk, NY, US) was utilized for statistical analysis of the collected data,

\section{Results}

Of the $347 / 500$ (response rate 69.4\%) medical students, 85 (24.5\%) were from the preclinical students ( $2^{\text {nd }}$ and $3^{\text {rd }}$ years), and $262(64.5 \%)$ were enrolled in the clinical group $\left(4^{\text {th }}\right.$ to $6^{\text {th }}$ years of MBBS). The majority of students 330 (94.1\%) were unmarried, only 17 of them, i.e., 4.9\%, were married. Analysis of the data revealed that medical textbooks, essential versions of basic medical books, online resources, and online version of books were used more frequently by the clinical group as compared to the preclinical students. Teacher-provided lecture handouts and lecture notes taken during classes were being equally used by both groups. There was a significant difference in the opinion on the usefulness of different resources between both groups.

Jameel et al. This is an open access article distributed under the terms of the Creative Commons Attribution License CC-BY 3.0., which permits unrestricted use, distribution, and reproduction in any medium, provided the original author and source are credited.

Students faced difficulty in understanding the English language, observed more in the preclinical years as compared to relatively groomed clinical students. The preclinical group could not understand the teaching material in books due to a weaker understanding of the English language. Social media software was used for keeping both groups busy, but clinical students also used social media for academic purposes. More than half of the participants from the 
preclinical and almost one-third from the clinical years admitted that their teachers recommended them for relevant medical textbooks. An encouraging trend was observed in most preclinical group students: they found teaching modalities, such as problem-based learning (PBL) and other academic activities, as a trigger to promote book reading.

\section{Conclusion}

Our results show that the students in the clinical phase had a more methodical approach to professional studies and a difference in spare-time activities.

Categories: Internal Medicine, Medical Education

Keywords: medical students, study habits, reading resources, social media, clinical sciences, basic sciences

\section{Introduction}

Medical education is one of the toughest fields and needs plenty of time, dedication, passion, and concentration. Mastery of the subject depends upon the approach that the students adopt for learning. One of the most common complaints among medical students is the excessive burden of the curriculum and frequent assessments [1]. Acquiring knowledge and essential clinical skills are fundamental for the grooming of the developing health professional. Reading is the most crucial way of learning throughout the medical carrier [2]. It all depends on how efficiently a medical student has mastered his/herself in time management, concentration, reading speed, study habits, and retaining knowledge by proper revision sessions [3].

Medical education traditionally involves training activities, which prepare a young, raw individual in becoming a member of the noble society of humans [3]. It involves biphasic training, i.e., preclinical and clinical. Preclinical training grooms individuals with background knowledge, which remains the backbone of one's critical decisions throughout the professional career [4-5]. Preclinical or basic sciences teaching, including anatomy, physiology, pharmacology, biochemistry, and other subjects, are said to have three basic responsibilities. First, to provide the backbone for future clinical reasoning; second, to facilitate management decisions; these may be of a medical or surgical nature; and third, to support plus encourage improvements in tricky healthcare situations [6].

The lengthy curriculum and frequent assessment also influence the students' approach to learning and studying habits and spare-time activities. A study demonstrated a significant relationship between study habits and performance in professional assessments [7]. The abundance of knowledge in the field of medical sciences compels medical students to adopt different learning approaches for passing the exams, and this is significantly influenced by the way of assessment as well [8]. The learning requirements of a medical student are partly different at various stages of professional study. In most medical schools, the standard practice of medical teaching is aligned in such a way that in preclinical years, the students usually learn in the classrooms, with occasional introductory visits to the hospitals, while during the training in clinical years, the main focus is on bedside teaching [9]. Students acquire clinical skills while being part of multidisciplinary healthcare teams in hospitals. It has been observed that females are more attentive and time-sparing as compared to boys in preclinical years when most of the information is provided through textbooks and related methods [10]. A recent study reported that female medical students study books more frequently as compared to males [11]. The grades of preclinical students mostly depend on how much time they spare for reading and retaining knowledge [12].

Medical students face several academic stressors like lengthy academic curriculum or syllabus, 
frequent periodic exams, theoretical and practical exams, and a lack of time for other activities [13]. To overcome these stresses, medical students adopt different approaches to cover the extensive curriculum and pass frequent exams. There is a lack of published data regarding the comparison of the medical students' approaches in the preclinical and clinical training years towards professional studies in SA. Only a few studies explored this topic in the region [14-15]. This study aims at a recognition of the differences in study habits, approach to teaching resources, and spare-time activities of medical students in the preclinical and clinical training period in King Abdulaziz University (KAU), Jeddah, Saudi Arabia.

\section{Materials And Methods}

Study sampling was carried out over three months in 2017 at King Abdulaziz University, Jeddah. The study was conducted on two campuses, i.e., Faculty of Medicine, Rabigh, and KAU Jeddah. The preclinical group comprised $2^{\text {nd }}$ and 3 rd-year students, and $4^{\text {th }}, 5^{\text {th }}$, and 6 th-year students were part of the "clinical" group. In Saudi Arabia, medical students spend their first year (foundation year) in training in the English language, chemistry, and biology, along with other basic premedical subjects. The students belonged to the Faculty of Medicine, Rabigh and Jeddah campuses of the KAU. The Rabigh campus is a comparatively newly established campus of KAU and situated $150 \mathrm{~km}$ away from Jeddah city. The participants were briefed in detail regarding the aim of the study, and verbal consent was obtained from all the participants. The Ethical Committee of King Abdulaziz University Jeddah granted research approval.

All the students had access to an online questionnaire, having detailed queries regarding the evaluation of the students' approaches towards professional studies and how their spare time was being utilized in different hobbies and activities. The questions were constructed according to the Likert scale. Multiple-choice questions were also included so that a wide choice could be available to the students for their responses. The questionnaire was presented to around 500 medical students, both males and females, of all the classes of MBBS. Initially, the questionnaire was tested on a pilot group of 30 students, and Cronbach alpha was calculated (Cronbach alpha $=0.81$ ). Our consultant team consisted of a medical educationist and a senior professor who confirmed the content validity. We modified our questionnaire according to the suggestions of our experts.

SPSS, Version 21 (IBM Corp., Armonk, NY, US) was utilized for statistical analysis and variables were expressed as frequencies and percentages. The Chi-square test was used to find out significant differences among different variables and $\mathrm{p}$-value $<.05$ was taken as significant.

\section{Results}

Of the $347 / 500$ (response rate 69.4\%) medical students, 85 (24.5\%) were from the preclinical students ( $2^{\text {nd }}$ and $3^{\text {rd }}$ years), and 262 (64.5\%) were enrolled in the clinical group ( $4^{\text {th }}$ to $6^{\text {th }}$ year of MBBS). Most students, 330 (94.1\%), were unmarried; only 17 of them, i.e., 4.9\%, were married.

The clinical group, as compared to the preclinical group, used medical books, essential versions of basic medical books, online resources, and online version of books more frequently. Teacherprovided lecture handouts and lecture notes taken during classes were being equally used by both groups (Table 1). 


\section{Cureus}

\begin{tabular}{|c|c|c|c|c|c|c|}
\hline & & & & & \\
\hline & & $\mathrm{n}$ & $\%$ & $\mathrm{n}$ & $\%$ & \\
\hline \multirow{5}{*}{ Medical textbook } & Rarely & 45 & $45.0 \%$ & 55 & $55.0 \%$ & $<0.001^{*}$ \\
\hline & $<30$ Mins/day & 13 & $19.4 \%$ & 54 & $80.6 \%$ & \\
\hline & 30-60 Mins/day & 10 & $12.2 \%$ & 72 & $87.8 \%$ & \\
\hline & 60-90 Mins/day & 8 & $18.6 \%$ & 35 & $81.4 \%$ & \\
\hline & >90 Mins/day & 9 & $16.4 \%$ & 46 & $83.6 \%$ & \\
\hline \multirow{5}{*}{ Essential version of a basic medical text book } & Rarely & 46 & $33.8 \%$ & 90 & $66.2 \%$ & $0.006^{*}$ \\
\hline & $<30$ Mins/day & 25 & $24.0 \%$ & 79 & $76.0 \%$ & \\
\hline & 30-60 Mins/day & 7 & $13.0 \%$ & 47 & $87.0 \%$ & \\
\hline & 60-90 Mins/day & 4 & $17.4 \%$ & 19 & $82.6 \%$ & \\
\hline & $>90$ Mins/day & 3 & $10.0 \%$ & 27 & $90.0 \%$ & \\
\hline \multirow{5}{*}{ Online sources: } & Rarely & 25 & $33.3 \%$ & 50 & $66.7 \%$ & $0.018^{*}$ \\
\hline & <30 Mins/day & 34 & $26.8 \%$ & 93 & $73.2 \%$ & \\
\hline & 30-60 Mins/day & 18 & $20.0 \%$ & 72 & $80.0 \%$ & \\
\hline & 60-90 Mins/day & 1 & $3.3 \%$ & 29 & $96.7 \%$ & \\
\hline & >90 Mins/day & 7 & $28.0 \%$ & 18 & $72.0 \%$ & \\
\hline \multirow{5}{*}{ Online version of textbook } & Rarely & 44 & $30.8 \%$ & 99 & $69.2 \%$ & $0.035^{\star}$ \\
\hline & $<30$ Mins/day & 24 & $25.0 \%$ & 72 & $75.0 \%$ & \\
\hline & 30-60 Mins/day & 10 & $16.7 \%$ & 50 & $83.3 \%$ & \\
\hline & 60-90 Mins/day & 7 & $21.9 \%$ & 25 & $78.1 \%$ & \\
\hline & >90 Mins/day & 0 & $0.0 \%$ & 16 & $100.0 \%$ & \\
\hline \multirow{5}{*}{ Medical websites } & Rarely & 26 & $32.1 \%$ & 55 & $67.9 \%$ & 0.005 \\
\hline & $<30$ Mins/day & 39 & $27.7 \%$ & 102 & $72.3 \%$ & \\
\hline & 30-60 Mins/day & 12 & $18.2 \%$ & 54 & $81.8 \%$ & \\
\hline & 60-90 Mins/day & 6 & $16.2 \%$ & 31 & $83.8 \%$ & \\
\hline & >90 Mins/day & 2 & $9.1 \%$ & 20 & $90.9 \%$ & \\
\hline \multirow{5}{*}{ Pocketbooks } & Rarely & 58 & $32.2 \%$ & 122 & $67.8 \%$ & $0.005^{*}$ \\
\hline & $<30$ Mins/day & 14 & $16.7 \%$ & 70 & $83.3 \%$ & \\
\hline & 30-60 Mins/day & 10 & $22.2 \%$ & 35 & $77.8 \%$ & \\
\hline & 60-90 Mins/day & 3 & $11.5 \%$ & 23 & $88.5 \%$ & \\
\hline & >90 Mins/day & 0 & $0.0 \%$ & 12 & $100.0 \%$ & \\
\hline
\end{tabular}




\section{Cureus}

\begin{tabular}{|llllllll}
\hline & Rarely & 8 & $21.1 \%$ & 30 & $78.9 \%$ & 0.491 \\
& $<30$ Mins/day & 20 & $27.4 \%$ & 53 & $72.6 \%$ & \\
\hline Lecture handouts & 30-60 Mins/day & 18 & $18.6 \%$ & 79 & $81.4 \%$ & \\
& 60-90 Mins/day & 20 & $27.4 \%$ & 53 & $72.6 \%$ & \\
& $>90$ Mins/day & 19 & $28.8 \%$ & 47 & $71.2 \%$ & \\
& Rarely & 13 & $20.6 \%$ & 50 & $79.4 \%$ & 0.182 \\
& $<30$ Mins/day & 29 & $20.7 \%$ & 111 & $79.3 \%$ & \\
Lecture notes taken in the class & $30-60$ Mins/day & 17 & $24.3 \%$ & 53 & $75.7 \%$ & \\
& $60-90$ Mins/day & 14 & $36.8 \%$ & 24 & $63.2 \%$ & \\
& $>90$ Mins/day & 12 & $33.3 \%$ & 24 & $66.7 \%$
\end{tabular}

\section{TABLE 1: Comparison of time spent/day by the preclinical and clinical students in}

using different resources (students were allowed to tick more than one item)

*. The Chi-square statistic is significant at the .05 level.

There was a significant difference in the opinion regarding the usefulness of different resources between both groups (Table 2).

\begin{tabular}{|c|c|c|c|c|c|c|}
\hline & & \multicolumn{4}{|c|}{ Level of Study } & \multirow[t]{3}{*}{ P-value } \\
\hline & & \multicolumn{2}{|c|}{ Pre-Clinical } & \multicolumn{2}{|l|}{ Clinical } & \\
\hline & & Count & Row N \% & Count & Row N \% & \\
\hline \multirow{3}{*}{ Medical textbook } & Not useful at all & 16 & $47.1 \%$ & 18 & $52.9 \%$ & $<0.001$ \\
\hline & Somewhat useful & 48 & $31.4 \%$ & 105 & $68.6 \%$ & \\
\hline & Extremely useful & 21 & $13.1 \%$ & 139 & $86.9 \%$ & \\
\hline \multirow{3}{*}{ Essential version of a basic medical text book } & Not useful at all & 25 & $48.1 \%$ & 27 & $51.9 \%$ & $<0.001$ \\
\hline & Somewhat useful & 42 & $23.9 \%$ & 134 & $76.1 \%$ & \\
\hline & Extremely useful & 18 & $15.1 \%$ & 101 & $84.9 \%$ & \\
\hline \multirow{3}{*}{ Online sources } & Not useful at all & 11 & $39.3 \%$ & 17 & $60.7 \%$ & 0.018 \\
\hline & Somewhat useful & 40 & $29.0 \%$ & 98 & $71.0 \%$ & \\
\hline & Extremely useful & 34 & $18.8 \%$ & 147 & $81.2 \%$ & \\
\hline & Not useful at all & 20 & $30.8 \%$ & 45 & $69.2 \%$ & 0.003 \\
\hline Online version of textbook & Somewhat useful & 49 & $29.9 \%$ & 115 & $70.1 \%$ & \\
\hline
\end{tabular}




\section{Cureus}

\begin{tabular}{|c|c|c|c|c|c|c|}
\hline & Extremely useful & 16 & $13.6 \%$ & 102 & $86.4 \%$ & \\
\hline \multirow{3}{*}{ Online journal article } & Not useful at all & 34 & $37.0 \%$ & 58 & $63.0 \%$ & 0.002 \\
\hline & Somewhat useful & 43 & $22.2 \%$ & 151 & $77.8 \%$ & \\
\hline & Extremely useful & 8 & $13.1 \%$ & 53 & $86.9 \%$ & \\
\hline \multirow{3}{*}{ Medical websites } & Not useful at all & 16 & $51.6 \%$ & 15 & $48.4 \%$ & $<0.001$ \\
\hline & Somewhat useful & 40 & $29.2 \%$ & 97 & $70.8 \%$ & \\
\hline & Extremely useful & 29 & $16.2 \%$ & 150 & $83.8 \%$ & \\
\hline \multirow{3}{*}{ Pocketbooks } & Not useful at all & 37 & $50.0 \%$ & 37 & $50.0 \%$ & 0.000 \\
\hline & Somewhat useful & 38 & $22.4 \%$ & 132 & $77.6 \%$ & \\
\hline & Extremely useful & 10 & $9.7 \%$ & 93 & $90.3 \%$ & \\
\hline \multirow{3}{*}{ Journal articles (print version } & Not useful at all & 36 & $27.7 \%$ & 94 & $72.3 \%$ & 0.522 \\
\hline & Somewhat useful & 42 & $23.1 \%$ & 140 & $76.9 \%$ & \\
\hline & Extremely useful & 7 & $20.0 \%$ & 28 & $80.0 \%$ & \\
\hline \multirow{3}{*}{ Lecture handouts } & Not useful at all & 10 & $35.7 \%$ & 18 & $64.3 \%$ & 0.004 \\
\hline & Somewhat useful & 23 & $15.6 \%$ & 124 & $84.4 \%$ & \\
\hline & Extremely useful & 52 & $30.2 \%$ & 120 & $69.8 \%$ & \\
\hline \multirow{3}{*}{ Test Preparation textbooks } & Not useful at all & 18 & $34.6 \%$ & 34 & $65.4 \%$ & 0.170 \\
\hline & Somewhat useful & 36 & $21.8 \%$ & 129 & $78.2 \%$ & \\
\hline & Extremely useful & 31 & $23.8 \%$ & 99 & $76.2 \%$ & \\
\hline \multirow{3}{*}{ Lecture notes taken in the class } & Not useful at all & 6 & $24.0 \%$ & 19 & $76.0 \%$ & 0.142 \\
\hline & Somewhat useful & 23 & $18.5 \%$ & 101 & $81.5 \%$ & \\
\hline & Extremely useful & 56 & $28.3 \%$ & 142 & $71.7 \%$ & \\
\hline
\end{tabular}

TABLE 2: Comparison of the preclinical and clinical students' perception regarding usefulness of different resources (students could tick more than one item)

*. The Chi-square statistic is significant at the .05 level.

Preclinical students faced difficulty in understanding the English language; they admitted that because of this problem, they did not readily understand the professional language of books. The trend of avoiding textbooks was observed more in preclinical students as compared to students in clinical years, as they must depend more on medical literature in dealing with different clinical challenges as compared to lecture notes by the teachers. The preclinical students had many other excuses to avoid textbook reading like feeling it is difficult to focus on 


\section{Cureus}

a relevant topic, not finding enough time to go through the voluminous books, or facing difficulty in finding appropriate resources according to their specific needs (Table 3).

\begin{tabular}{|c|c|c|c|c|c|c|}
\hline & & \multicolumn{4}{|c|}{ Level of Study } & \multirow{3}{*}{ P-value } \\
\hline & & \multicolumn{2}{|c|}{ Pre-Clinical } & \multicolumn{2}{|c|}{ Clinical } & \\
\hline & & $\mathrm{n}$ & $\%$ & $\mathrm{n}$ & $\%$ & \\
\hline \multirow{3}{*}{ I don't like reading material written in English } & Agree & 53 & 62.3 & 15 & 5.7 & $<0.000$ \\
\hline & disagree & 23 & 27.0 & 243 & 92.7 & \\
\hline & Don't know & 9 & 10.5 & 4 & 1.5 & \\
\hline \multirow{3}{*}{ I have problem in understanding the textbook } & Agree & 39 & 45.8 & 20 & 7.6 & $<0.000$ \\
\hline & disagree & 30 & 35.2 & 242 & 92.3 & \\
\hline & Don't know & 16 & 18.8 & -- & --- & \\
\hline \multirow{3}{*}{ I don't have enough time to read textbook } & Agree & 56 & 65,8 & 16 & 6.1 & $<0.000$ \\
\hline & disagree & 15 & 17.6 & 246 & 93.8 & \\
\hline & Don't know & 14 & 16.4 & -- & -- & \\
\hline \multirow{3}{*}{ I don't know what to focus in reading textbook } & Agree & 60 & 70,5 & 7 & 2.6 & $<0.000$ \\
\hline & disagree & 25 & 29.5 & 237 & 90.4 & \\
\hline & Don't know & -- & -- & 18 & 6.8 .0 & \\
\hline \multirow{3}{*}{ I don't know the best resources } & Agree & 25 & 29.4 & 10 & 3,8 & $<0.000$ \\
\hline & disagree & 55 & 64,7 & 245 & 93.5 & \\
\hline & Don't know & 1 & 1.17 & r & 2.6 & \\
\hline \multirow{3}{*}{ I feel difficulty to find sources appropriate to my level } & Agree & 41 & 48.2 & 12 & 4.5 & $<0.000$ \\
\hline & disagree & 38 & 44.7 & 235 & 89.6 & \\
\hline & Don't know & 6 & 7.0 & 15 & 5.7 & \\
\hline
\end{tabular}

\section{TABLE 3: Comparison of the preclinical and clinical students experience regarding} reading the textbooks

*. The Chi-square statistic is significant at the .05 level.

Most clinical year students 202 (77.0\%) committed to spending most of their spare time while studying the medical literature. Similar trends were observed in response to questions about outdoor games and watching sports on TV. The use of social media software was equally popular between the groups. Almost $98 \%$ of preclinical and $76 \%$ of clinical students mentioned 
WhatsApp and Facebook as their major way of passing time (Figure 1).

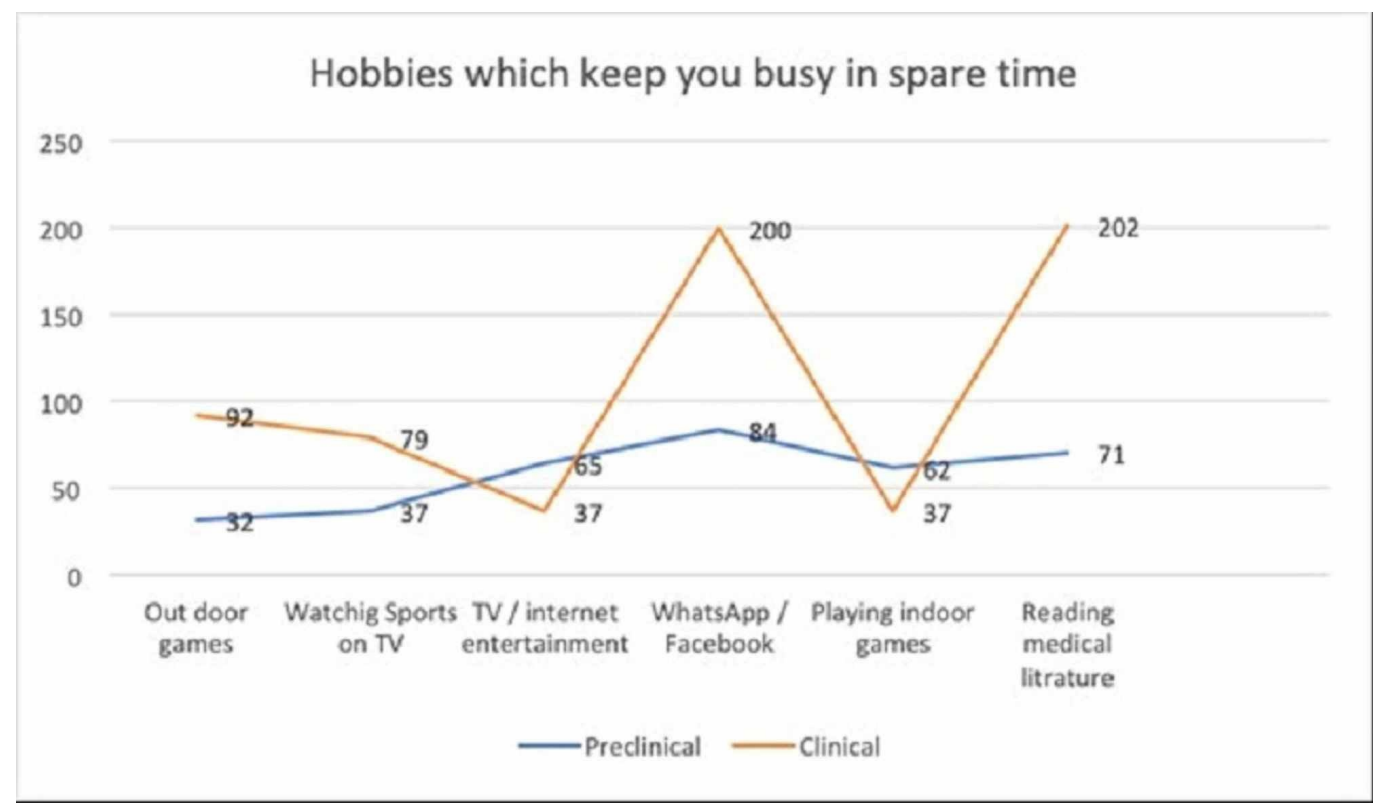

FIGURE 1: Recreational activities among preclinical and clinical years medical students

More than half of the participants, i.e., 52 (61\%), of the preclinical and 99 (38\%) from the clinical year admitted that their teachers recommended them for relevant medical textbooks. Significantly, many students of the preclinical group, 82 (92\%), thought that problem-based learning (PBL) and other active learning activities promoted the student's interest in book reading to a great extent. However, only a small group of clinical students also mentioned it as a useful teaching tool. As the preclinical students consulted the library relatively quite often, they appreciated that all the books in the college library were updated regularly and, mostly, the textbooks were of the latest edition.

\section{Discussion}

In the clinical phase, the students are exposed to new clinical queries because they are more inclined towards online journals and medical websites [16]. A similar trend was seen in our study where $91 \%$ of our clinical students preferred medical websites along with other online sources. Interestingly, the clinical students in our cohort were given enough time to use medical textbooks as compared to the preclinical students. Similarly, it has been observed by Kauffman (2015) that because of the change in learning climate after exposure to patients, the students in the clinical phase give importance to the latest editions of the textbooks and to recent information provided by medical websites and online journal articles [17].

Mon et al. (2014) pointed out the preference of preclinical medical students towards the subject related textbooks, lecture handouts, and test preparation books. The primary purpose being the success in assessment tasks frequently posed to preclinical students [18]. However, we observed a relatively different trend in our study that the clinical students outnumbered the preclinical group in the study of almost all the study resources. It was statistically highly significant while comparing both groups on medical book reading, essential version of the books, pocketbooks, medical website, and online source study. One of the reasons for the difference in opinion between preclinical and clinical students could be that in clinical years' teaching, learning and assessment are patient-oriented and it cannot be learned by lecture 
handouts. Moreover, with the passage of time, they become accustomed to reading and understanding textbooks and realizing that without studying books better and a deep understanding of the subject, mastering the topic is not possible. Additionally, studying textbooks facilitates their chances of passing the Saudi Licensing Exam and fellowship exams as well. It may be explained in a way that by attaining maturity in the transition from the preclinical to the clinical phase and with the help of their seniors, the clinical group students gradually develop an interest in the habit of study [19].

In the Middle East, all the newly admitted medical students undergo training in English and pre-medical science subjects like biology, physics, and organic chemistry in the first year, called the foundation year [20]. In our study, we observed, through student's feedback, that understanding written English remains the biggest hurdle for our students. Around $67 \%$ of the clinical group students complained of their poor understanding and frequent consultation of the dictionary to find out meanings. Almost a similar percentage of students committed their disliking for teaching material written in English. The pre-clinical group in whom this problem is of more intensity tried to ignore the question by avoiding a clear-cut response. This problem has also been observed in other studies in Saudi Arabia, and their recommendation was to introduce English teaching from the school level [21-22]. We suggest that the incorporation of an English language session at least once weekly in the first two preclinical years will help improve our students' understanding and speaking skills.

There is an apparent difference between the preclinical and clinical year students' approach to spare-time activities. It could be due to the difference in the burden of the studies, teaching and learning strategies, and assessment approaches. In the clinical years, it is more patients0oriented like short and long cases, clinical presentations, case-based learning, and objective structured clinical examinations. These differences compel clinical year students to adopt different approaches. In our study, we observed that social media software like Facebook and WhatsApp kept both groups of students busy most of the time, and it was especially marked in the clinical group, which can be explained as follows. In clinical training, the students prefer professional groups and most of the messages are sent via WhatsApp. This notion gets strengthened by the finding of a similar number of clinical student's interest in an online medical literature study. Alwagait et al. mentioned both the negative and positive aspects of social media addiction in the younger generation of the Middle East and especially of Saudi Arabia [23]. According to recent studies, it was pointed out that KAU students are extensively using different social media [24-25].

The present study found that textbook reading and frequent visits to medical websites were consistently observed in the clinical group and the majority of successful preclinical students were taking class notes and reading the lecture handout provided by the teachers. Around $80 \%$ of preclinical students admitted that all the latest subject-specific books are available in the college library, and the teachers and study guides provided at the start of each module recommended the study of subject-specific books. Abdulghani et al. (2014) observed that the students who excel in the medical profession are frequently those who develop purposeful reading habits and are close observers of recent developments in medical fields [26].

Our results also show that students are more influenced and inclined toward available online resources. However, the problem is the selection of appropriate websites and tools from the available abundant websites. In this regard, the teacher can play an important role by guiding the students' in choosing authentic tools and websites. Students are very eager, motivated, and dedicated; they need proper direction in their studies to excel in the field.

It is suggested that each department in the college should select the appropriate online tools and websites related to that course and provide the lists to the students in the study guide, so 
the students can take benefit from these websites. Furthermore, students must be encouraged to learn English from the school level so that they may not find the English language unfamiliar during their professional studies.

\section{Limitations}

There are certainly some limitations to our present study. The main limitation lies in being a single center, with a small sample size and a questionnaire-based study, so the chances of the student's response biases are present.

\section{Conclusions}

Our results show that students in the clinical phase had a more methodical approach to professional studies and a difference in spare-time activities. The present seriousness of students towards their professional studies on exposure to the clinical environment is a very positive sign and needs to be encouraged.

\section{Additional Information \\ Disclosures}

Human subjects: Consent was obtained by all participants in this study. Unit of Biomedical Ethics. King Abdulaziz University Jeddah issued approval 2/38/22268. The Committee recommends granting permission of approval to conduct the project. Animal subjects: All authors have confirmed that this study did not involve animal subjects or tissue. Conflicts of interest: In compliance with the ICMJE uniform disclosure form, all authors declare the following: Payment/services info: All authors have declared that no financial support was received from any organization for the submitted work. Financial relationships: All authors have declared that they have no financial relationships at present or within the previous three years with any organizations that might have an interest in the submitted work. Other relationships: All authors have declared that there are no other relationships or activities that could appear to have influenced the submitted work.

\section{References}

1. Gazzaz ZJ, Baig M, Al Alhendi BSM, et al.: Perceived stress, reasons for and sources of stress among medical students at Rabigh Medical College, King Abdulaziz University, Jeddah, Saudi Arabia. BMC Med Educ. 2018, 18:19. 10.1186/s12909-018-1133-2

2. Silverman J, Kurtz S, Draper J: Teaching and Learning Communication Skills in Medicine. CRC Press, London; 2016. 10.1201/9781315378398

3. Harden RM, Laidlaw JM: Essential Skills for a Medical Teacher: An Introduction to Teaching and Learning in Medicine. Elsevier Health Sciences, Edinburgh; 2017.

4. Burns CA, Lambros MA, Atkinson HH, Russell G, Fitch MT: Preclinical medical student observations associated with later professionalism concerns. Med Teach. 2017, 39:38-43. 10.1080/0142159X.2016.1230185

5. Schiller JH, Stansfield RB, Belmonte DC, Purkiss JA, Reddy RM, House JB, Santen SA: Medical students' use of different coping strategies and relationship with academic performance in preclinical and clinical years. Teach Learn Med. 2018, 30:15-21. 10.1080/10401334.2017.1347046

6. Yilmaz ND, Velipasaoglu S, Ozan S, et al.: A multicenter study: how do medical students perceive clinical learning climate? [EPub]. Med Educ Online. 2016, 21:10.3402/meo.v21.30846

7. Baig M, Tariq S, Rehman R, Ali S, Gazzaz ZJ: Concept mapping improves academic performance in problem solving questions in biochemistry subject. Pak J Med Sci. 2016, 32:801-805. 10.12669/pjms.324.10432

8. Baig M, Ali SK, Ali S, Huda N: Evaluation of multiple choice and short essay question items in basic medical sciences. Pak J Med Sci. 2014, 30:3-6. 10.12669/pjms.301.4458 
9. Wechter E, O'Gorman DC, Singh MK, Spanos P, Daly BJ: The effects of an early observational experience on medical students' attitudes toward end-of-life care. Am J Hosp Palliat Med. 2015, 32:52-60. 10.1177/1049909113505760

10. Al Husaini ZAE: Knowledge, attitude and practice of reading habit among female medical students, Taibah University. J Taibah Univ Med Sci. 2013, 8:192-198.

10.1016/j.jtumed.2013.09.004

11. Jameel T, Gazzaz ZJ, Baig M, et al.: Medical students’ preferences towards learning resources and their study habits at King Abdulaziz University, Jeddah, Saudi Arabia. BMC Res Notes. 2019, $12: 30.10 .1186 /$ s13104-019-4052-3

12. Al Shawwa L, Abulaban AA, Merdad A, et al.: Factors potentially influencing academic performance among medical students. Adv Med Educ Pract. 2015, 6:65. 10.2147/AMEP.S69304

13. Sayedalamin Z, Halawa TF, Baig M, et al.: Undergraduate medical research in the Gulf Cooperation Council (GCC) countries: a descriptive study of the students' perspective. BMC Res Notes. 2018, 11:283. 10.1186/s13104-018-3381-y

14. AlHaqwi AI, Van der Molen HT, Schmidt HG, Magzoub ME: Determinants of effective clinical learning: a student and teacher perspective in Saudi Arabia. Educ Health. 2010, 23:369.

15. Fida NM, Farouq M, Alamawi D, Kamfar H: Undergraduate medical students' perceptions of their learning experience in pediatric rotation at King Abdulaziz University Medical College in Jeddah, Saudi Arabia. Med Teach. 2017, 39:37-44. 10.1080/0142159X.2016.1254747

16. Imran M, Shamim MS, Baig M, Farouq M, Gazzaz ZJ, Al-Mutairi OM: Tale of two cities: comparison of educational environment of two colleges (Jeddah and Rabigh) affiliated with one university. J Pak Med Assoc. 2016, 66:316-319.

17. Kauffman H: A review of predictive factors of student success in and satisfaction with online learning. Res Learn Technol. 2015, 23:26507. 10.3402/rlt.v23.26507

18. Salem RO, Al-Mously N, Nabil NM, Al-Zalabani AH, Al-Dhawi AF, Al-Hamdan N: Academic and socio-demographic factors influencing students' performance in a new Saudi medical school. Med Teach. 2013, 35:83-89. 10.3109/0142159X.2013.765551

19. Berkhout JJ, Teunissen PW, Helmich E, van Exel J, van der Vleuten CP, Jaarsma DA: Patterns in clinical students' self-regulated learning behavior: a Q-methodology study. Adv Health Sci Educ. 2017, 22:105-121. 10.1007/s10459-016-9687-4

20. Al-Sayes FM, El-Deek BS, Ayuob NN, Al-Ahwal HM, Barefaa AS: Perception of medical students during the foundation year at King Abdulaziz University. JKSUS. 2012, 19:73-84.

21. Alrashidi O, Phan H: Education context and English teaching and learning in the Kingdom of Saudi Arabia: an overview. Engl Lang Teach. 2015, 8:33-44. 10.5539/elt.v8n5p33

22. Kaliyadan F, Thalamkandathil N, Parupalli SR, Amin TT, Balaha MH, Ali WH: English language proficiency and academic performance: a study of a medical preparatory year program in Saudi Arabia. Avicenna J Med. 2015, 5:140-144. 10.4103/2231-0770.165126

23. Alwagait E, Shahzad B, Alim S: Impact of social media usage on students' academic performance in Saudi Arabia. Comput Human Behav. 2015, 51:1092-1097.

10.1016/j.chb.2014.09.028

24. Sayedalamin Z, Alshuaibi A, Baghaffar M, Almutairi O, Jameel T, Baig M: Utilization of smartphone related medical applications among medical students at King Abdulaziz University, Jeddah: a cross-sectional study. J Infect Public Health. 2016, 9:691-697. 10.1016/j.jiph.2016.08.006

25. Baig M, Gazzaz ZJ, Atta H, Alyaseen MA, Albagshe AJ, Alattallah HG: Prevalence and attitude of university students towards mobile phone use while driving in Jeddah, Saudi Arabia. Int J Inj Contr Saf Promot. 2018, 25:372-377. 10.1080/17457300.2018.1431940

26. Abdulghani HM, Al-Drees AA, Khalil MS, Ahmad F, Ponnamperuma GG, Amin Z: What factors determine academic achievement in high achieving undergraduate medical students? A qualitative study. Med Teach. 2014, 36:43-48. 10.3109/0142159X.2014.886011 